\title{
4. Mobility and its consequences: the 2006 enumeration in the north-east Arnhem Land region
}

\section{Frances Morphy}

\section{Introduction}

This case study is constructed from an anthropological perspective. An anthropological analysis has a particular kind of contribution to make in a situation such as a census enumeration, in which members of an encapsulated cultural minority are interacting with the institutions of the encapsulating state. I want to convey how the census enumeration appears to the Yolngu - particularly the Community Coordinators (CCs) and collector-interviewers (CIs) - in order to understand some of the problems that arise and what their possible solutions might be.

The census, being a dwelling-based count, is founded on assumptions about the characteristics of populations that fit sedentary settler societies such as mainstream Australia, but which do not fit populations such as the Yolngu, who, as I have argued elsewhere (Morphy 2007), behave in 'radically uncontained' ways. I am concerned to explore the consequences of this for the Indigenous Enumeration Strategy (IES) in general, and its impact on the role of the Census Field Officer (CFO) in particular.

I have also chosen to structure the major part of this case study as a chronological narrative of the count in four phases, to convey a sense of just how difficult a task it is to 'capture' this mobile population, and as a background to what might sometimes appear to be critical comments about how the 2006 enumeration was managed. There is no self-evident and easy strategy; however, in the way in which it is currently constituted, the CFO's job is all but impossible. I am not asserting necessarily that the current collection methodology results in a significant over or under-count, rather that the expectations put on the CFO are unrealistic and unattainable, and this makes the job unnecessarily stressful.

I also want to demonstrate that the mobility of the population, although radical, is not random; it takes place within particular parameters. Once these are understood, it becomes easier to devise more efficient enumeration strategies. I will argue that such strategies will depend crucially on making best use of local knowledge, not only of the CCs and CIs, but of the staff-Indigenous and non-Indigenous - of local organisations whose primary task it is to provide local populations with services and infrastructure. The patterns of mobility that I describe below are peculiar to this particular region and cannot necessarily be 
generalised to others. In each region, however, there are organisations that are repositories of knowledge about the characteristics of local population mobility. I will be suggesting that the Australian Bureau of Statistics (ABS) needs to engage in long-term relationships with these organisations and help them build their capacity to better understand the local dynamics of mobility. This in turn will deliver to the ABS, come census time, key individuals who will be in a position to help in significant ways with the organisation of the census enumeration.

\section{Localities}

In order to comply with confidentiality requirements, I use letters of the alphabet to designate the major hub settlements in the Yolngu-speaking area, and for the homeland communities I use the letter of the hub settlement to which they are attached, followed by a number. To further disguise the area of the case study, I have assigned a number of homelands to hub settlements that differ from the one that, in reality, is their service centre.

The Yolngu-speaking area contains roughly 6000 Aboriginal people - most of whom are speakers of one of the Yolngu languages - and also the mining town of Nhulunbuy. There are six hub settlements in the area, ranging in size from more than 1000 people (Galiwin'ku/Elcho Island) to just more than 200 people (Gunyangara/Ski Beach). These have been assigned the letters A-F. There are two other settlements - $\mathrm{G}$ and $\mathrm{H}-$ outside the Yolngu area proper that will also figure in this account.

The homelands that form the focus of this case study are Al-12 and $\mathrm{Cl}-5$ - that is, 17 of the estimated 76 inhabited homelands in the Yolngu-speaking area. ${ }^{1}$ The CFO for the Yolngu-speaking area was responsible for the enumeration at all of the Yolngu settlements and homelands, as well as Groote Eylandt and Numbulwar and its homelands. There are, in total, more than 10,000 Aboriginal people scattered throughout this remote area of 37,000 square kilometres.

The CFO had hoped to cover settlements $\mathrm{A}$ and $\mathrm{C}$ and all their attached homelands in the first week of the enumeration, starting on 6 July. He had decided that the best strategy was to try to complete the count in one subregion at a time, so that he and/or the Assistant CFO could be present for most of the count, leaving to start the CC and CI training in the next subregion only when the count was nearly complete. Unfortunately, things did not go to plan; the count in communities $\mathrm{A}$ and $\mathrm{C}$ and their attached homelands was still incomplete many weeks later. In theory, the CFO's initial strategy was a sensible one in terms of logistics and efficient use of time. In practice, it proved completely unworkable.

\footnotetext{
1 This estimate is taken from the list that the CFO was given for reference at the beginning of the 2006 count.
} 


\section{Funerals: a major cause of mobility}

No Yolngu funeral is a perfunctory affair. ${ }^{2}$ Despite the fact that most Yolngu choose 'Uniting Church' over 'Traditional beliefs' in response to the census question on religion, funerals are a major focus of a rich ceremonial system founded on traditional beliefs. In the pre-mission past, primary burial-interment or placement on a platform — was a swift affair. The more major ceremony after death was secondary reburial when the bones were retrieved and, after a period of being carried around by close relatives in a bark container, were placed in a hollow-log coffin. These secondary ceremonies were often much longer than the first, involved regional gatherings and took place at times of year when resources permitted the concentration of large numbers of people. They took place only after negotiations among all the relevant kin about the form of the ceremony and the final placement of the hollow-log coffin.

Missionisation, beginning in the mid 1930s, led to the discontinuation of secondary reburial, so that the ceremonial focus began to move to the primary burial. These ceremonies began to be more lengthy affairs, although still not overly so until the introduction of a new technology - the portable morgue. Beginning in the mid 1970s, Yolngu funerals have become exponentially longer and more elaborate affairs. Politics surrounding control of the ceremony and the final resting place of the deceased have intensified, in part because, unlike the organisation of a secondary reburial in the past, negotiations are contingent on the circumstances and time of the death and are compressed in time. Funerals have become the site of community politics par excellence.

The funeral of an important and senior person can attract up to 400 people from a wide region, and take several months. Although the 400 will not be present all of that time, funerals are a major cause of continual intra-regional mobility on a massive scale. In some years - and 2006 was a case in point - funerals are a continual presence. There might be several going on at the same time, although one is often delayed until after another is finished so that they follow one another almost without pause.

It is logistically impossible and inappropriate to undertake an enumeration at a place where a funeral is happening. During the course of a funeral, close relatives of the deceased person will camp at the site of the funeral for the duration. Others will come and go, usually making sure that they attend certain important points of the ceremony, particularly the last few days leading up to the burial itself. It is fair to say that the organisation of and attendance at funerals takes precedence over everything else, particularly for senior ceremonial leaders and certain categories of relatives of the deceased person.

2 For a detailed ethnography of a Yolngu funeral (for a small child), see Morphy (1984). 


\section{The count, phase one: 6 July to 3 August}

When the CFO arrived at Settlement A, there were four funerals under way in the immediate region: one at A itself, one at homeland A10 and two at other large predominantly non-Yolngu settlements in the wider region ( $\mathrm{G}$ and $\mathrm{H}$ ). The CFO had difficulty recruiting local CIs for A and C. Using lists of people supplied to him by the council offices of $\mathrm{A}$ and $\mathrm{C}$, he found and trained one CC for Community A and two for Community $\mathrm{C}$, and two potential CCs for the homelands attached to Community $\mathrm{A}$. He and the CCs tried and failed to recruit CIs for the training. It had been estimated back at the Census Management Unit (CMU) that eight CCs and 21 CIs would be needed for the count in these two communities and their associated homelands, so this was not an auspicious start.

Having got the count under way in sections of the main settlements that were not affected directly by the funeral, the CFO set off down the track - accompanied by myself and the Assistant CFO - to survey the situation in some of the homelands. We drove into A7 (a three-dwelling homeland) towards evening. It was empty - everyone was at the funeral at A. The next day we called in at A8, which has a usual resident population of about 80 . It too was deserted-everyone was at the large funeral happening at nearby A10. ${ }^{3}$

It was decided to return to these communities after the funerals were over and people had returned. The CFO had been warned before leaving A-by staff of local organisations and by the CCs he had recruited - that these homelands would be empty, or nearly so. Because people know how everyone is related to everyone else, they can predict with a fair degree of certainty which people will be attending which funerals. At this stage, the $\mathrm{CFO}$ - who had not previously worked in the Yolngu area, apart from undertaking the Community Housing and Infrastructure Needs Survey (CHINS) - had not fully appreciated the potential impact of funerals on population movement, and wanted to see for himself.

We then called in at A9. Not many people were there - some were at the funerals at $\mathrm{A}$ and A10. The daughter of the community leader was seriously ill in hospital and her parents had just returned from seeing her there. Nevertheless, the community leader and his wife were happy to be recruited as the CC and CI for A9 and to conduct the count once everyone had returned from the funerals. They also volunteered to enumerate A10 once the funeral there was finished. The CFO arranged to come back in a few days to conduct the training, and we set off further down the track in an optimistic frame of mind.

\footnotetext{
3 At its height, this funeral of a senior man, which was politically contentious, attracted more than 400 people from a region the size of Wales. In turn, however, members of the host community were themselves absent - at yet another funeral in the wider region at E2.
} 
We drove on to the largest homeland in the area, C3, where the usual resident population is in the region of 160 . The plan was to recruit another CC and some CIs here to cover C3, C4 and C5 (another large homeland), since these three are close to each other and their inhabitants are closely interrelated. The CFO was successful in recruiting two CCs (one of whom had been a CI during the 2001 Census) and three CIs. After their training, however, as the CCs and CIs began going from house to house, it became evident that at least one-third of the population of $\mathrm{C} 3$ was away, at four different funerals (the ones at A, G, H and A10), or visiting relatives, predominantly at $\mathrm{A}$, and several people were about to leave for the final part of the funeral at A10. In two cases, the entire household was away and their dwellings stood empty. It was decided to do a first count here, go on to $\mathrm{C} 4$ and $\mathrm{C} 5$, then return to $\mathrm{C} 3$, hopefully to catch people as they returned from the various funerals. In the meantime, all those who were away were put down as 'persons temporarily absent' (PTA), including on the forms for the empty dwellings. There were at least 20 'visitors' present - people visiting their kin from other communities (predominantly C2, C4, C5 and the settlements of A, C, B and G). ${ }^{4}$ These were counted as visitors in the main section of the form. The $\mathrm{C} 3$ team was about to go to $\mathrm{C} 4$ and $\mathrm{C} 5$, and there was a possibility that some of the visitors would be returning to these communities at the same time, but the $\mathrm{CFO}$ and the $\mathrm{C} 3$ team were confident that no double-counting would result because everyone would be able to keep track of who had already been counted as visitors at $\mathrm{C} 3$.

I stayed with the C3 team, and drove them on to C4 and C5 when they had finished their first pass at $\mathrm{C} 3$. The CFO and his Assistant returned to A to try to get the count going in the other $\mathrm{A}$ and $\mathrm{C}$ homelands, and to offer support to the single remaining $\mathrm{CC}$ at $\mathrm{A}$, who at this point was endeavouring to enumerate this sizeable community on her own. Back at A, the CFO discovered that the entire populations of A 3 and $\mathrm{A} 4$ were at $\mathrm{A}$ for the funeral there. They were enumerated at A 'as if' they were in their dwellings in A3 and A4. I will return to the reason why this happened below.

\section{The burdens of literacy}

In the meantime, the two CCs recruited and trained to cover the other A and C homelands had gone to the final phases of the funeral at A10. They were under a heavy obligation to attend, as close relatives of the deceased, and this took precedence over their duties to the census. This brings me to a separate but

\footnotetext{
4 The pattern of mobility captured here in snapshot was very similar to that observed at the same
} homeland during the 2001 Census (see Morphy 2002). 
equally important theme: the drop-out rate of Indigenous CCs and CIs is often a cause for comment, but it is necessary to understand why they drop out. ${ }^{5}$

Most Yolngu do not keep diaries. They might sign up in good faith to be a CC or CI, for example, only to be reminded a few days later that they have a medical appointment with a specialist who is paying one of their periodic visits to the area. For a homelands person, this means a plane ride into A. One of the CIs at C3 found himself in this situation. There are, however, more systemic reasons why people are likely to fall by the wayside during the count.

The people who are most likely to be recruited as CCs and CIs in a region such as this are the rare individuals with the requisite levels of literacy in English. They are 'better educated' in a Western sense, and this means:

- they might already have a job

- because they tend to be among the most able, intelligent and competent people, they are in demand for local events (such as funerals) and their status in their own community is judged by their commitment to participating in such events

- at the same time, they are expected-by their relatives and by local non-Indigenous staff of organisations - to represent the interests of the community at the interface between the Yolngu world and the encapsulating society

- they often have a sense of 'civic duty' that impels them to take part in the non-local event that is the census, despite competing demands on their time, because they have an understanding of the local consequences of more global processes.

People like this are in constant danger of burn-out. Aboriginal communities are conceived of popularly as places where people sit around on 'sit-down' Community Development Employment Projects (CDEP) money and do nothing much. The situation of the general population is the subject of a different study - in which this view would be disputed. The situation of the most able and the most Western-educated - and therefore most literate - is, however, as stressful as any in mainstream society in terms of competing and conflicting demands on their time.

As with the CFOs, I would argue, the current operation of the IES puts many local CCs and CIs in a no-win situation. The enumeration process necessitates a sustained and intensive effort, and, since it often proves impossible to recruit sufficient numbers of people for the size of the population, it can involve a very heavy workload.

${ }^{5}$ For example, during the training of the CFOs, it was recommended that they try to recruit more CCs and CIs than they really needed, so that if some people dropped out there would be others to fill their places. 
In the way in which the IES is organised at present, this is an intractable problem. Competing demands often force CCs and CIs to abandon their census work - temporarily or permanently - and this in turn places heavier demands on the remaining CCs and CIs, and also on the CFO, who must then somehow recruit and train replacements. If he or she has already moved on to another subregion, clearly there is the potential for the census effort to stall completely. This is what happened in the case-study area and, as a result, the count in the A and C homelands - with the exception of the area covered by the $\mathrm{C} 3$ team - was a prolonged and tortuous affair. The relative smoothness of phase one was a bit of a false dawn. I conclude this section with two short case studies that illustrate the conflicting demands on people acting as CIs and CCs. Some details have been changed to protect their anonymity.

\section{Case one ${ }^{6}$}

One of the CCs recruited originally for the A and C homelands was back at Community A after the completion of the funeral at A10. He was ready and willing to restart work as a CC/CI. The $\mathrm{CFO}$ had in the meantime gone to start the count in a different region, leaving the Assistant CFO at A. She was very pleased to see the CC again, as his help was sorely needed at A and in some of the $\mathrm{A}$ and $\mathrm{C}$ homelands, where the count had temporarily ceased. We made plans to leave for A2 - another homeland that had been visited once and found to be empty of inhabitants (they too had been at the funeral at A10, but were now known to have returned home). We had heard that the previous evening there had been a death, but the identity of the person who had died had not been confirmed. Just as we were preparing to leave for A2, two policemen arrived at the CC's house, asking him to identify the body. An hour later, he returned with the news that the dead person was one of his clansmen, a close 'father' of his. Although visibly upset, he insisted that he would carry on work because he realised that his help was badly needed. We were just about to leave when a group of senior clan leaders called him over. They were anxious to begin planning the funeral, which was to take place at A8, and wanted him to be a part of the discussion. (Most of the inhabitants of A8 were back home now after the end of the funeral at A10, and this meant precision planning was now needed for the count there because once the funeral ceremony began it would not be possible to go there.) It was impossible for the CC to refuse, so the count at A2 was postponed yet again.

\section{Case two}

The attrition rate among the CCs at A and C, who had never been numerous in the first place, had necessitated the ad hoc training of extra people, whenever

6 In all these examples details have been changed to protect the identity of the specific individuals concerned. 
they could be found. One person who already had a part-time job volunteered to work on her days off. She was assigned a workload in A, which she completed conscientiously and efficiently. It was then decided to use her as the CI for some of the remaining $\mathrm{A}$ and $\mathrm{C}$ homelands. With her help, the count at A6 was completed. (One entire A6 household was still away at A12, where the funeral had just ended. This household was not followed up until the forms had been returned to the CMU in Darwin, when it was realised that they had been missed.) The CFO and his Assistant were pleased and relieved that the homelands count was getting under way again. Then, unfortunately, the daughter of the leader of the A9 community died in hospital. This particular CI and her family were related to the dead woman in such a way as to make it imperative that they become involved in organising her funeral, which included arranging for the body to be flown back from Darwin. The family at A9 wanted a short funeral and they needed to arrange it quickly because the girl's mother was herself due to go to Darwin for an operation. The CI tried valiantly to continue her census work, but after a couple of days it all became too much. The family was relying on her, as a literate person, to complete the bureaucratic arrangements and she still had her part-time job on top of that. And, despite the family's desire for a quick and uncomplicated funeral, 'Yolngu politics' about where the funeral should take place began to manifest themselves. On one occasion, when this CI was helping someone to fill in the form for their household, she was reproached for doing this work when she should be attending to funeral matters. She asked to be relieved of her obligations to the census until after the arrangements for the funeral had been completed. After the funeral was over, she came back to work as a CI.

\section{The count, phase two: 3-7 August}

On 3 August, nearly a month after the beginning of the census count in this area, my field notes revealed the state of play to be as follows.

The CFO had just left to organise the count at $\mathrm{H}$, leaving the Assistant CFO behind to continue supervising the work in the $\mathrm{A} / \mathrm{C}$ area.

C3 had been done - in two stages; one household was still away, and was discovered later to have been counted at $\mathrm{A}$ as usual residents of a household there (see Case three); a few other individuals were still away at G. C4 had been done, but one house was empty, as people were at the funeral at A10. C5 had been done, but some people were away at the funeral at A10; others were visiting relatives at $\mathrm{B}$. The residents of A3 and A4 had been counted at A because they were attending a funeral there, but were counted 'as if' they were at home. A6 had been done, but one household was absent at the A10 funeral. A5 had been done, although it was later discovered that some A5 people had been counted twice - as usual residents - at both A and A5. 
Community A was, apparently, nearly done. There were still a few houses to do, but the CC who had done most of the work on her own was completely burnt out, and besides, as a schoolteacher, her normal employment was about to resume.

$\mathrm{Cl}$ had been established as empty-its residents had been counted as 'usual residents' in a house at A.

Al was still to be done; it was geographically closer to $\mathrm{F}$ than to $\mathrm{A}$, and the $\mathrm{CFO}$ intended to organise the count from F. In the event, Al was nearly overlooked (see Chapter 8). A2's residents were apparently still not home and were proving elusive. Some residents of A7, which had been empty when first visited, were still at the funeral at A10, while the whereabouts of others was unknown. All the residents of A8 were still at the A10 funeral. A girl's funeral was now taking place in A9; there was a major funeral at A10; the usual residents of A11 were at funerals at A9 and A10; and A12 had not yet been visited. A CI who was resident at A but whose family belonged to $\mathrm{C} 2$ had been recruited to count $\mathrm{C} 2$, but so far had not produced anything and was proving elusive. C6, a large homeland, had not yet been visited.

The current workforce was: the C3 team, but their work was finished and the logistics of using them elsewhere were complicated by distance; the CC who had almost single-handedly counted A was burnt out; two CCs, who were finishing $\mathrm{C}$ and who were then going to do C6; and two other CCs, and one CI, all of whom were unavoidably involved at the funerals at A9 and A10, but who would probably become involved again once the funerals were over. The CI who was allegedly looking after $\mathrm{C} 2$ was an unknown quantity.

I recorded 'this week's new problems' as: a suicide at A (leading to the closing of part of the community), the funeral at A9 and the Garma Festival, which was potentially another source of major population movement in the Yolngu-speaking region, and which also attracted substantial numbers of people from $\mathrm{H}$.

Within the wider area of his responsibility, the CFO had not yet visited, let alone begun work at, any of the following settlements and their associated homeland communities: B, D, E, F and G. It was clear that he was not going to be able to devote much more time or energy to the $\mathrm{A} / \mathrm{C}$ area.

After a couple of days of enforced inactivity, during which the Assistant CFO caught up on her paperwork, she and I visited the man who was regarded as the leader of the community at A12. He had a job that kept him at A during the week, and he was counted at A as a usual resident there. We learned from him that the other residents of A12 - his two sons and their families - were on their way into A to shop, so we waited until they arrived and the Assistant CFO filled in their forms with them, counting them as usual residents of their two households at A12 rather than as 'visitors' to the house at A where they would be staying for the next day or so. 
A couple of days later, the funeral at Al0 finally wound up and the much shorter funeral at $\mathrm{A} 9$ also finished. One $\mathrm{CC}$ had remained at A10, but the other CC and the CI who had been at these funerals came back to A. Phase three was about to begin. Before I describe the events of this phase, I will touch on an issue hinted at in the preceding paragraph: in this context, who is a usual resident and who is a visitor?

\section{Problems of definition: 'usual resident' and 'visitor'}

Some Yolngu people who have jobs in the main settlements but who have a strong attachment to a clan homeland - a situation that is likely to become more and more common - find it hard to categorise themselves as a 'usual resident' of one place rather than the other. ${ }^{7}$ This must be a dilemma for certain people in the mainstream as well, but in the Yolngu case the attachment to their clan lands is more than just one of sentiment; it is the foundation of their social and spiritual identity. For Yolngu, the distinction 'my country/not my country' is more salient than the distinction 'resident/visitor'. This is also a factor in many other Indigenous societies, and it can affect how people categorise themselves on their census forms (see also Chapter 8).

People do not necessarily think of themselves as either 'residents' or 'visitors' in the places where they happen to be at census time, and for those who are highly mobile it is difficult for them and for others who might be answering the census questions on their behalf to decide how they should be categorised. At one end of the spectrum are the dhukarrpuyngu ('people of the track'): young men (and increasingly young women) who are highly mobile, and who cannot really be classified as residents anywhere. They are not, however, homeless in the mainstream sense of the term. Wherever they go in their travels they will be staying in the households of more sedentary relatives.

Dhukarrpuyngu have the potential to either be missed completely or double-counted - forgotten because their movements during a rolling count mean that they are not present in any community at the time that it is counted, or double-counted because they are present in more than one place during the count, and are included in the households where they are staying, either as a 'resident' or as a 'visitor'. Some children are also highly mobile. There are the children of young and/or 'bad' (a Yolngu judgment) mothers, who circulate between the dwellings of other relatives, typically of the grandparental generation. Others are children who just 'love to travel and visit their family', and do so when an opportunity presents itself. Children as young as five or six

\footnotetext{
7 The Howard government's intention is clearly to put pressure on working-age adults leaving clan homelands to take up jobs in major settlements and towns. This intention became evident first in 2005, with changes to the CDEP program to focus much more on training for 'real' jobs and exiting participants into non-CDEP employment (DEWR 2005a, 2005b). In July 2007, as part of the current National Emergency Response, the government announced the abolition of the CDEP program.
} 
have considerable autonomy, and parents have no anxiety about them as long as they are with trusted family members. In the enumerations I observed, I was able to pick up several instances where dhukarrpuyngu and mobile children were double-counted or not counted at all.

While it is possible, with a bit of local knowledge and a bird's-eye view, to track down instances of double-counting, it is far harder to pick up on people who have not been counted at all. To do so requires having a mental map of an entire community or region, and to notice absence rather than presence. No one involved in the census counts, from the CIs to the CMU, is in a position in which they have an overview of an entire regional population and simultaneously have the knowledge to pick up on absences. The CIs and the CCs have the local knowledge but not the overview, and the CFO and the CMU have the overview but lack the knowledge.

At the other end of the spectrum are individuals who are permanent residents either at a homeland or at a settlement. On the homelands, these tend to be the senior men of the community and their close families. Although their residency status tends to be unambiguous, this does not mean lack of mobility, for it is precisely such people who tend also to have responsibility for the organisation and conduct of ceremonies, and they are often away from home. In addition, only one of the A/C homelands has its own store, so even the most sedentary are often away from home shopping 'in town'. This often entails an overnight stop, and sometimes a more prolonged stay if the money runs out or the vehicle breaks down. During the count at C3, for example, an average of three small plane-loads of people came and/or went shopping each day, and vehicles were coming and going constantly.

In between the two extremes are a large number of people who, for a variety of reasons to do with their family affiliations, personal circumstances or personal preferences are hard to categorise as residents of any one particular place. I give two rather different examples in the short case studies below.

\section{Case three}

At $\mathrm{C} 3$ there is one household where the father of the family has a job at A. The rest of the family resides at $\mathrm{C} 3$, and he joins them at weekends. At the time of the count, the house was empty - the entire family had gone to A 'for a holiday' because it was the school holidays. The CCs and CIs at C3 considered the whole family, including the father, to be residents of their house at C3, so the household form was filled in with the help of relatives. They were first put down as PTA, but then it was decided that they might not be counted at A since they had gone from there to the funeral at A10. They were moved 'inside the form' - that is, they were counted as if they had been at C3 during the count. On double-checking the form completed at the house at A where the father of the 
family usually stayed, I found that they had all been counted there as well-as residents-before leaving for A10. Their Yolngu names had been used on the C3 form but their English given names had been used on the form at A, and their ages had been estimated at $\mathrm{C} 3$ while their dates of birth were entered at $\mathrm{A}$. In a final twist, the parents - but not the rest of the family - appeared on a form completed at A10, once the funeral was finally over. By this time, the family in question had gone back to $\mathrm{A}$. This form had been filled in by someone who was normally resident in the house at $\mathrm{A}$, but who was still at A10. The CI had given her the form to fill in herself. She treated the form as the household form for her house in A, rather than counting herself as a 'visitor' at A10, and included the C3 husband and wife as usual residents of that household. In effect, then, the house at A ended up with two forms, and these forms had different but overlapping sets of 'usual residents'.

\section{Case four}

When it was possible, eventually, to do the count at A10 there were still many 'visitors' there who had not yet returned home after the funeral. It was decided that these people should be counted, just in case they were not caught later when they went home (the count had already been completed at some of the places, such as A, where they were usual residents). Only those who stated that they had definitely been counted elsewhere were excluded. There was one middle-aged man there from $\mathrm{Bl}$, a homeland that was not in the remit of the CCs and CIs who were covering the $\mathrm{A} / \mathrm{C}$ homelands. $\mathrm{Bl}$ was not, however, his clan homeland, and he was often also to be found at the settlement of B. Later, at the CMU in Darwin, I looked at the forms from Bl and from B and found that this man had been triple-counted. As well as featuring as a visitor at Al0, he had been counted as a PTA ('visiting Bl and then at funeral at A9') on a form at B and moved 'inside the form' on the grounds that he had not been at Bl, but at the funeral at A9 when the count was done there. Finally, he had been counted as a PTA at Bl ('at funeral at A10') and moved back inside the form on the grounds that he would not be counted at A10. He was identified by his English given name on one form, by one of his Yolngu names on another form and by another of his Yolngu names on the third form. At A10, he had himself given his date of birth, but on the B and Bl forms his age had been estimated. The estimates differed by a decade, and neither of these imputed ages coincided with his real year of birth.

During the course of the count - a period of about four weeks - this man's real movements had been: $\mathrm{B}$ to $\mathrm{B} 1, \mathrm{~B} 1$ to $\mathrm{A} 10, \mathrm{~A} 10$ to B, B to B1, B1 to A9, and finally A9 to A10. Such a pattern of movement is commonplace for senior Yolngu men with ceremonial responsibilities. 


\section{The wider political context}

As noted earlier, the 2006 Census took place at a time of considerable change in Indigenous affairs. In particular, the 'sustainability' of small homelands was being questioned and they were being portrayed in some circles as 'cultural museums' where the CDEP program had created a culture of dependency and fostered a 'recreational' lifestyle. Some commentators - and politicians - were advocating forms of social engineering that would 'encourage' people to leave the homelands and remote communities for 'real' jobs in the towns. The CDEP program was in the process of being refashioned, with less of an emphasis on 'community development' and an increasing emphasis on 'training for real jobs'. Yolngu were aware of these developments and many were very worried about their implications. Many of their community organisations were under severe pressure as they attempted to adjust to the new demands that were being placed on them, particularly by the changes to the CDEP program.

Yolngu had been among the first people to embrace the homelands movement of the early 1970s - indeed, they were active instigators of it. They began the move back to the homelands from the missions before the time when, under the Whitlam government, the movement began to receive government support under the rubric of 'self-determination'. Most homelands Yolngu want to continue living on their homelands. Many of them have been talking for some time about their desire to build local economies so that their young people will have jobs. Recent developments had shown them that they could no longer rely on government to 'look after' them, and had at the same time highlighted their vulnerability to externally imposed change.

For better or worse, most Yolngu perceived the census as an instrument of government, so the count took place in a politically charged atmosphere. I observed much more questioning of its purpose than in 2001, and more cynicism about the uses to which the data might be put. There was occasional resistance or politically motivated responses to some of the questions, particularly those concerning residence, and, interestingly, the ability to speak English. In 2001, Yolngu were not seeing fluency in English as a political issue - they tended to estimate their own and other people's abilities using objective criteria and, from an English speaker's point of view, they tended to overestimate people's ability. In 2006, I heard the leader of one homeland, whose spoken English is reasonably fluent, exhorting the CIs-loudly, so that many people could hear him, in English:

Don't put me down as [speaking English] 'well', put me down as 'not well', and the same for everyone. It's time this government learnt the truth about their education system. We need better education for us and our children so we can start our own businesses and they can get real jobs right here, in this community. 
The politicisation of the 'residence' issue was manifested in two ways. Some people questioned the notion of a single place of residence. One man commented, for example: 'I live in both places [A and A12]. Sometimes at one, sometimes at the other, because of my job here [at A]. I can't say which is "most of the time". I should put both.'

More significantly, the political climate led to several homelands being enumerated 'as if' their residents were at the homeland rather than where they really were when they were filling out the form. People reasoned that they were only temporarily absent, for funerals or other reasons, but that if they allowed themselves to be enumerated as 'visitors' at A, where they really were at the time, the 'government will say that we're not really living at our home, they will say it's empty'. Some of those who were included as residents of these homelands were indeed people who spent most of their time there, but others were people who went backwards and forwards between A and the homeland, much like the family from $\mathrm{C} 3$ discussed earlier. There was therefore potential for double-counting.

In most cases, the 'as if' practice did not lead to double-counting because these were small communities, all of the members of which were at $\mathrm{A}$ at the time of the count. They had made a joint and conscious decision to be counted as if they were at home, so they were not also counted as visitors at A. In one case (A11), however, there is a household whose 'usual residents' commute between All and the community of $\mathrm{B}$ because one of them has a job in the store at B. They were at $B$ when the other usual residents of All decided to count themselves 'as if' they were at Al1. The people at A also filled in a form for the B household. A crosscheck of the forms from B later at the CMU in Darwin revealed that this family had been double-counted: at $\mathrm{A}$ as residents of $\mathrm{Al1}$, and at $\mathrm{B}$ as residents of B.

Such an 'as if' count is not, however, the same as counting people at a place. Instead, it represents people's idea of who would have been there had the count really happened there. In such circumstances, certain categories of people tend to be forgotten - most significantly children. I was able to satisfy myself that the children of at least one couple failed to gain a mention in one of these 'as if' counts - I do not know whether they were counted elsewhere.

\section{The count, phase three: 8-14 August}

With the funeral at A10 finally over, the Assistant CFO decided that we should do the count there before the CFO returned from $\mathrm{H}$. We set off from $\mathrm{A}$ on 8 August, with the $\mathrm{CC}$ who had just come back from the funeral there, hoping to meet up with the second CC, who was still there. When we arrived there were still many 'visitors' in a total of 22 tents, as well as most of the 'usual residents' in five dwellings. As the Assistant CFO and the two CCs began work, it quickly 
became evident why counting people at a funeral is not only inappropriate but also inadvisable. At the house nearest to the airstrip there were three clusters of two, three and five tents (see Figure 4.1). The first cluster, of two tents, contained the household from A previously mentioned in Case Three. The 'Person 1 ' for this family decided, as we have seen, to count the household 'as if' they were back at A. The second cluster, of three tents, contained most of the family that we had missed at $\mathrm{C} 4$. Since they had definitely not been counted there, the tents were designated as a 'temporary dwelling' and the occupants were enumerated as 'visitors'. The largest cluster, of five tents, contained mostly people who were from A (and the man from Bl mentioned in Case Four) and who had not yet returned there. It was assumed that they had not yet been counted and they were enumerated as 'visitors' to the dwelling (making this a 25-person household form).

Fig. 4.1 The 'tent city' at A10, August 2006

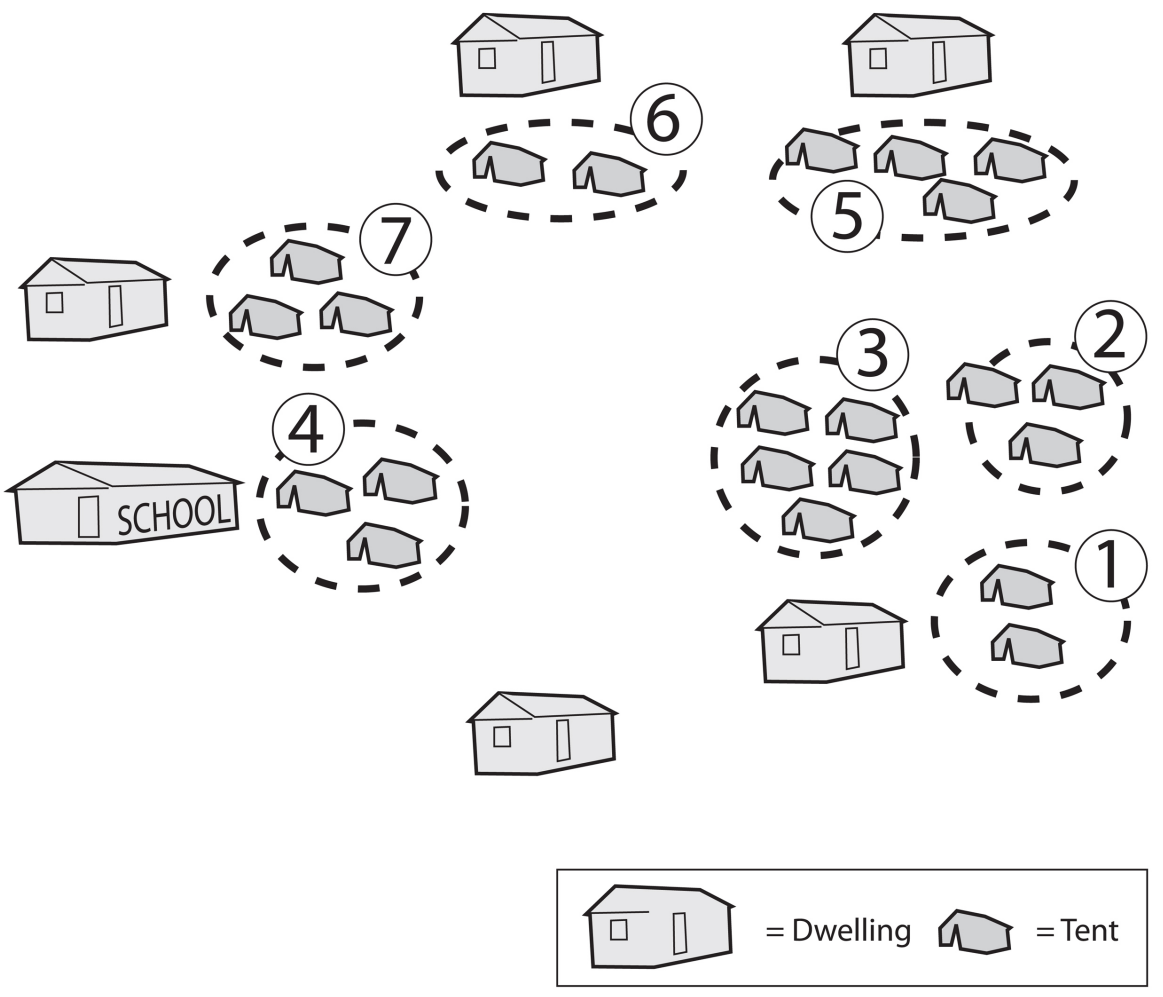

Notes: 1) Household from A counted 'as if' at A; 2) visitors from C4, counted as a 'temporary dwelling'; 3) visitors from A and B3, counted as visitors to adjoining Al0 dwelling; 4) visitors from A8; 5) and 6) occupants said to have been counted at A, therefore not counted at Al0; 7) status unknown. 
The 18 occupants of three tents pitched near the school building turned out to be people from a single household at A8, the large nearby homeland that had been empty when we first visited it back in early July. The other residents of A8 had already left for home because, we were told, the personal effects of a person who had died elsewhere were about to arrive there, signalling the beginning of another funeral ceremony. The school tent-dwellers were about to return to A8, which had not yet been counted, but the Assistant CFO decided to play it safe and enumerate them there and then. She pondered whether they could be counted as 'visitors' in a 'temporary dwelling', or be counted 'as if' they were at home. In the end, they were counted as visitors.

The occupants of two other tent complexes (six tents in all) said they had been counted at A before coming to the funeral at A12. The Assistant CFO and the CCs, who were feeling a little overwhelmed at this point, were happy to take their word for it. There remained one tent cluster, the status of which I did not ascertain. They were either not counted or were counted as visitors to the nearby house.

In all, more than 90 people were counted at A12, the majority of them visitors. Somewhere between 20 and 40 were not counted, on the assumption that they had already been counted elsewhere. This was the most chaotic of the counts that I observed. No attempt was made to draw up a list of the dwellings and temporary tent dwellings (I made my own sketch map; see Figure 4.1). It was clear that the Assistant CFO and CCs were confused about who should and should not be counted. One CC thought only 'locals' should be counted, on the grounds that everyone who was there as a visitor should have been put 'inside the form' at their place of usual residence - that is, counted as if they were at home because of being at a place (the funeral) where they were unlikely to be counted. Strictly speaking, he was correct, because these were the instructions he had received in his training, and he was acting on the assumption that every $\mathrm{CC}$ and $\mathrm{CI}$ in the area had followed those instructions to the letter-which they had not. The situation was not, however, clear-cut because of the rolling nature of the count. There were in fact several kinds of 'visitors' present: those who had been counted elsewhere, either as residents or visitors; those whose home communities had already been counted in their absence and who might or might not have been put inside the form, depending on the proclivities of the CIs and CCs who had conducted the count there; and those whose communities had yet to be counted.

The count at Alo highlighted for me the full complexities of attempting a de facto count with principled exceptions (the instruction to count PTA as present if they were not likely to be counted elsewhere). Such an instruction, in the context of a rolling count and a population that evinces high mobility across a wide area, calls constantly for judgments to be made on the basis of insufficient information. An individual CI might be able to keep track of the people they 
have already counted, but they cannot know whether some of the people they have counted have or have not been counted elsewhere by other CIs. I will return to the PTA question in Chapter 7 (see also Appendix B).

The next day (9 August), the CFO returned to A, in order to pick up the Assistant CFO so that they could move on to start proceedings at Community E. We sat down to review progress and decide what should be done in their absence. The $\mathrm{CFO}$ was reasonably happy with the way the count was proceeding at $\mathrm{H}$, having enlisted the services of a 'floating' CFO whose task was to act as a backup in areas where extra help was needed. The floating CFO was still at $\mathrm{H}$ and would stay there until the count was over.

The places that had still not been accounted for were: A1, A2, A7, A8, A11, C2 and $\mathrm{C} 6$. It had already been decided that $\mathrm{Al}$ would be covered during the count of $\mathrm{F}$ and its associated homelands. It was decided that if I could find a willing CC or CI I would take them to do the count at A2. There were now said to be people back at A7, but they were possibly going on to A8, which was in full funeral mode. The latest local estimate for when this funeral would finish was 17 August, so it was decided to leave these two communities until the CFO and/or Assistant CFO returned to A. The CFO would, before he left, find the CCs who were supposed to be doing A11, C2 and C6 to check on progress.

In the event, the $\mathrm{CFO}$ could not find the CCs responsible for $\mathrm{A} 11$ and $\mathrm{C} 2$, and I also failed to locate them in the days that followed. One of them was the person I was hoping to take to A2. Nothing more happened in the $\mathrm{A} / \mathrm{C}$ homelands count - with the exception of the count at C6 - until 13 August, when I learned that the CI who had been instrumental in organising the girl's funeral at A9 was now back at A. She willingly agreed to come with me to A2, which was located on her clan country, and we went the next day.

When we arrived, there was a young woman and some small children at one house, but otherwise the whole community was out hunting. Fortunately - and somewhat atypically - everyone had gone to the same place and it was not too far away, although getting there involved a somewhat hair-raising drive along the beach. The count proceeded in a relaxed and amiable manner, to the accompaniment of feasting on fish, crab, stingray and shellfish. All in all, there were about 30 'locals' there and also a visiting family who stated positively that they had been counted at $\mathrm{C}$ by a named CC.

This count was an example of the IES working at its best. The CI, despite having been able to work only intermittently, was an efficient interviewer and understood the form well. She was well known to everyone present and her status as an owner of the land gave her a certain additional authority (as we were leaving, she saw a group of girls returning laden with fish, and was able to claim as of right a substantial proportion for herself). Doing the count at the hunting site was also a bonus: counts at homelands communities are frequently 
curtailed or hurried because people are anxious to go hunting, whereas this count could be fitted around the hunting activities of the group. The fact that the community members had returned, and that it was therefore worthwhile making the journey to count them, had been gleaned from people at A who were related to them. Finally, any non-local who had arrived to find that everyone had gone out hunting would not have known where to go to find them, or might have been hesitant to do so, whereas locating them was unproblematic for this CI.

At this point, it was time for me to return for a while to Darwin. I returned to A in the second half of September, for the fourth and final phase of the count.

\section{A Darwin interlude}

Once in Darwin, I began my work at the CMU (reported on in Chapter 7). From time to time, I heard from the CFO about progress in the rest of his region. He was beginning to sound pretty discouraged. In a phone call on 29 August, he told me he had returned briefly to $\mathrm{A}$ and $\mathrm{C}$ and had been unable to find any of the CCs or CIs who still had forms outstanding. There had also been problems with the non-Indigenous count at A, where he had entrusted some of the forms to a staff member of a local organisation for distribution to some of the local employees. This had not happened.

The count at $\mathrm{H}$ was complete, but it was five houses short. The floating CFO was now supervising the count at G, but progress was slow. The CFO had left his Assistant to finish up the count at D and F and things were not 'going real well'. He was going to $\mathrm{B}$, the final community in his region, where the count had not yet started. He thought he would be back in Darwin the next week.

He said he was finding the same problem everywhere: not enough qualified and committed people to undertake the work - 'Checking the forms takes forever. You really have to push them, people aren't enthused.'

On 9 September I was at the CMU when the CFO called in to his line manager to say that he was not coming to Darwin immediately. His manager reported that he 'sounded very flat'. He had trained 17 people at B, but only one was left, and they had counted only eight houses so far.

The CFO did come to Darwin later, for the debriefing of the CFOs. I discuss my observations of that debriefing in the first part of Chapter 7. He then went back into the field. He subsequently had some conversations with the CMU about my possible role in the final phase of the count in the $\mathrm{A} / \mathrm{C}$ homelands. He envisaged that I would go to A8 with whoever was available in the way of CIs and supervise the count there. His line manager at the CMU decided, in consultation with Canberra, that what he was proposing necessitated my being signed up as a CC, rather than being classified as an impartial observer. I agreed to this on the condition that my status as CC applied only to this particular phase of the count. 
I had mixed feelings about this development. The boundary between participant and observer, for an anthropologist, is the fulcrum of the anthropological approach to fieldwork and to the analysis of social and cultural processes. The anthropological project is to become part of a process - to 'see it from inside' - while simultaneously preserving a sense of distance that allows for objective analysis. From an anthropological perspective, the 'observer's paradox' - the fact that the observer's presence has an effect on what is observed - is part of the data. Thus far my active role had been mainly to act as a driver, to enable CCs and CIs to undertake the count in communities other than their own, but, at least in the case of the count at A2, force of circumstance had meant that it was I rather than the absent CFO and Assistant CFO who had selected the CI for the job. In practice, it is a short step from there to being a CC. My worry was that drawing a line in the sand at a particular point in this process of incorporation - although clearly necessary from an administrative point of view - would also affect the way in which my findings would be viewed.

\section{The count, phase four: 20 September}

The CFO's difficulties in making contact with the CCs had necessitated the introduction of backup forces. On 20 September, I flew in to A8 in the company of the CI who had conducted the count at A2 and a non-local Indigenous Assistant who had previously been helping to finish off the count at F. The funeral there had finished, but there were still several 'visitors' in tents who had stayed on for a while. ${ }^{8}$ Meanwhile, the CFO was attempting to deal with all the other outstanding lacunae in the $\mathrm{A} / \mathrm{C}$ area.

We counted nearly 90 people at A8. One household consisted of people who had been counted previously at A10. I had suspected that we would bump into them again and so had brought the A10 form with me, reasoning that if they were at home it would be better for them to be counted there and removed from the form at A10. I was also interested to see whether they would say that they had already been counted, and also whether the details on the two forms would differ. The Indigenous Assistant was assigned to their household. They did not say that they had already been counted, for the simple reason that they did not know they had been. At A10, the form that listed them had been filled in by a local CC, and only one person from the household helped with the form. The rest of the household had been out hunting at the time the form was filled in. Now, at A8, most of the household was present, but the person who had been interviewed at A10 was out hunting! Since I was officially a CC this time, I crossed all those present at A8 off the form that had been completed at A10. Four people were still at A10, so they were left as 'visitors' there.

\footnotetext{
8 There were now two new funerals under way in the region, at C4 and C6, and there had been another funeral at A6 in my absence.
} 
The details supplied for certain individuals on the two forms did indeed differ. Because the Indigenous Assistant was not a Yolngu speaker, people gave him their English names, while at A10 their Yolngu names had been given. Estimates of people's ages differed wildly. One child was put down as a three-year-old at A10 and as a seven-year-old at A8. The ages of several of the adults differed by a decade. It seems highly probable that had I not been the CC in this instance, the members of this large household would have been double-counted. Because of the differences between the two forms, this double-counting would have been undetectable once the forms were back at the CMU in Darwin.

Since I was a CC this time, I took the opportunity to act as the CI for one household at A10. I wanted to experience for myself the CI's task. I chose a large household with several visitors who had not yet returned to A. There were 21 people in all, necessitating the use of two forms. Bearing in mind that I am a highly literate English speaker with some competence in the Yolngu languages and a fairly detailed knowledge of the community, I still found the task pretty gruelling. It took two full hours and keeping the interviewees focused on the task was difficult, when so much of the time I was simply ticking boxes rather than engaging with them.

I also had to make some tricky judgments about who to put on the form. There was a woman from A and some of her family who said they had not been counted at A, so I added them as visitors. This woman's brother and his family had also been at the funeral and had left only that morning. The sister said she thought her brother's family had not yet been counted. On balance, this was probable, because the man had a medical condition that necessitated him staying for prolonged periods in Darwin, and he and his family were often in transit between Darwin and A. It was possible that they had been at A on census night, and had missed being counted in Darwin. It was equally possible that they had been in Darwin when the count took place at A. I decided therefore to put them on the form as visitors and crosscheck the household form from A when I got back to the CMU. It transpired that they had, in fact, been counted at A. I do not know whether they were also counted in Darwin.

This was yet another instance of the complicating effect of the rolling count combined with mobility. I was in a unique position, with access to knowledge at the local level where the CIs were operating and at the more regional level, because of my observation of the entire process in the $\mathrm{A} / \mathrm{C}$ region and my access to the CMU in Darwin. I found myself in the same position as everyone else at the moment of the count: forced to make a more or less educated guess about whether or not to include someone on a form.

On our return to A, I found that the CFO was about to board a plane to Darwin. He had spent a nearly fruitless day looking for people. He was exhausted and feeling very unwell and was clearly unable to continue. He had contacted the 
CMU and a replacement team was on its way: a member of the CMU staff and one of the other CFOs. They had been at F, tying up the loose ends there. They arrived just before he left and he handed over his paperwork to them. I was leaving for Darwin the next day, so I spent the evening with the new team and the Indigenous Assistant, who had stayed on to help. We reviewed what still needed to be done or checked. On 20 September, therefore, more than 10 weeks after the count had started, it was still not fully completed.

\section{The role of local organisations: a missed opportunity}

The communities of $\mathrm{A}$ and $\mathrm{C}$ are host to three organisations that could potentially have been engaged more fully in the census exercise. These are the community councils of A and C, and the homelands resource organisation, based at A, which services the satellite homelands communities. All three were at the time Indigenous Housing Organisations (IHOs), so had been visited by the CFO during the CHINS exercise. The two community council organisations had originally provided the $\mathrm{CFO}$ with a list of potential CCs and CIs for the census. At the initial training session at Community $\mathrm{A}$, in a meeting room at A's community council office, one employee of $\mathrm{C}^{\prime}$ s community council came along to be trained as a CC. The homelands resource agency had originally agreed that one of its Yolngu employees would be available to act as a $\mathrm{CC}$, but in the event he was away at a course in Darwin when the CFO first arrived and because the CFO did not follow him up he never became engaged in census activities. The resource agency did provide an outside space in which the CFO could sit and do paperwork and also gave him access to the health database, which he attempted to use, unsuccessfully, to check missing date-of-birth information for homelands residents.

It is fair to say that these local organisations were busy, under-resourced and understaffed, and that they therefore did not volunteer proactively to play a more substantial role in the census exercise. For his part, the CFO was content to make use of the facilities they did provide, but he did not seek to involve them further. In failing to get them further involved, he deprived himself of two things that might have made his task much more manageable: the Yolngu and non-Yolngu staff of the homelands resource agency, in particular, were repositories of local knowledge and intelligence about people's whereabouts on a day-to-day basis; and, had he engaged them more proactively during the CHINS exercise in the business of recruiting potential CCs and CIs, he might not have found himself as shorthanded as he was.

Having said that, neither the CFO nor the organisations are to blame for this lack of mutual engagement. There is a structural problem to be addressed before a more fruitful relationship is possible. We return to address this issue in Chapter 9. 